Article

\title{
Determination of the Optimum Heat Transfer Coefficient and Temperature Rise Analysis for a Lithium-Ion Battery under the Conditions of Harbin City Bus Driving Cycles
}

\author{
Xiaogang $\mathrm{Wu}^{1,2, *}$, Siyu $\mathrm{Lv}^{1}$ and Jizhong Chen ${ }^{3}$ \\ 1 College of Electrical and Electronic Engineering, Harbin University of Science and Technology, Harbin \\ 150080,China; lvsiyu_ma15@hrbust.edu.cn \\ 2 State Key Laboratory of Power Transmission Equipment \& System Security and New Technology, \\ Chongqing University, Chongqing 400044, China \\ 3 State Key Laboratory of Operation and Control of Renewable Energy \& Storage Systems, \\ China Electric Power Research Institute, Beijing 100192, China; chenjz@epri.sgcc.com.cn \\ * Correspondence: xgwu@hrbust.edu.cn; Tel.: +86-13091885691
}

Academic Editor: Rui Xiong

Received: 25 September 2017; Accepted: 24 October 2017; Published: 27 October 2017

\begin{abstract}
This study investigated the heat problems that occur during the operation of power batteries, especially thermal runaway, which usually take place in high temperature environments. The study was conducted on a ternary polymer lithium-ion battery. In addition, a lumped parameter thermal model was established to analyze the thermal behavior of the electric bus battery system under the operation conditions of the driving cycles of the Harbin city electric buses. Moreover, the quantitative relationship between the optimum heat transfer coefficient of the battery and the ambient temperature was investigated. The relationship between the temperature rise $\left(T_{r}\right)$, the number of cycles $(c)$, and the heat transfer coefficient $(h)$ under three Harbin bus cycles have been investigated at $30{ }^{\circ} \mathrm{C}$, because it can provide a basis for the design of the battery thermal management system. The results indicated that the heat transfer coefficient that meets the requirements of the battery thermal management system is the cubic power function of the ambient temperature. Therefore, if the ambient temperature is $30{ }^{\circ} \mathrm{C}$, the heat transfer coefficient should be at least $12 \mathrm{~W} / \mathrm{m}^{2} \mathrm{~K}$ in the regular bus lines, $22 \mathrm{~W} / \mathrm{m}^{2} \mathrm{~K}$ in the bus rapid transit lines, and $32 \mathrm{~W} / \mathrm{m}^{2} \mathrm{~K}$ in the suburban lines.
\end{abstract}

Keywords: battery; thermal management; heat transfer coefficient; temperature rise models

\section{Introduction}

Thermal problems are a very critical issue in a lithium-ion battery, especially in high temperature environments. Therefore, controlling the temperature of the battery and establishing an appropriate thermal management system can make the lithium-ion battery safer and more stable, enhance its performance, and elongate its cycle life [1,2]. Many researchers have studied battery thermal management. For example, Abbas Tourani et al. [3] established a multi-dimensional thermo-electrochemical coupling model for a high-capacity lithium-ion battery and studied the thermal behavior of $\mathrm{LiMn}_{2} \mathrm{O}_{4}$ and $\mathrm{LiFePO}_{4}$ batteries using the finite element method. In addition, the heat distribution of the battery was obtained under high current conditions when the temperature increased at the end of the experiment. Chunjing Lin et al. [4] established a thermal model for a lithium-ion battery according to the internal resistance and entropy coefficient, which were experimentally obtained, and studied the temperature distribution and the increase in the temperature of the $\mathrm{LiFePO}_{4}$ cells under the conditions of mixed charge and discharge cycles. Fangming Jiang et al. [5] established a 
thermo-electrochemical coupling model to study the internal heat generation and heat loss processes during different charge and discharge cycles. Shuanglong Du et al. [6] established a three-dimensional thermal model based on the finite element theory and lumped internal heat generation principle to investigate the relationship between the discharge rate, total heat generation, and depth of discharge for the $\mathrm{LiFePO}_{4}$ battery. L H Saw et al. [7] established an empirical equation to describe the electrical characteristics of lithium-ion batteries, as well as a coupled lumped parameter thermal model to describe the thermal characteristics of the battery. The temperature of the battery was studied under the conditions of the driving cycles of the Urban Dynamometer Driving Schedule (UDDS), Highway Fuel Economy Driving Schedule (HWFET), and US06 Supplemental Federal Test Procedure (SFTP) to determine the flow rate of the cooling air that realizes the optimum thermal management of the battery system. Salvio Chacko et al. [8] established a three-dimensional electro-thermal coupling transient model by the finite element method to study the temperature changes in a lithium-ion polymer battery under high power and high ambient temperature conditions. Changfu Zou et al. [9] proposed a physics-based model based on the electrochemical, thermal, electrical, and aging dynamics of the lithium-ion battery and a novel framework of the battery based on partial differential equations (PDE) was developed. Changfu Zou et al. [10] developed a fully coupled electrothermal model and proposed a new algorithm to manage lithium-ion battery charging operations. The model can predict the temperature rise of the battery accurately and the algorithm can optimize the charging time and the temperature rise. Abbas Tourani et al. [11] applied a first principle thermo electrochemical model to study the heat generation of the battery. The effect of the heat transfer coefficient and ambient temperature on heat generation is summarized. These studies show the importance of establishing a thermal model for lithium-ion batteries and analyzing the relationship between their internal heat generation rate and temperature behavior under different working conditions for the researches of thermal management.

The temperature level of a lithium-ion battery directly affects its energy and power performance. The available capacity of the battery rapidly decreases at low temperature, while the battery has a potential safety problem at high temperature [12]. The heat transfer coefficient represents the amount of heat transfer by convection between the surface of the battery and the surrounding air. The change in the battery temperature is highly affected by the surface heat transfer coefficient [13]. Moreover, the heat transfer coefficient is an important index of the battery thermal management system. Therefore, it can help in the design of the battery pack material, size, internal ventilation, cooling air duct, and air vent. Referring to [11], there may be a relationship between the heat transfer coefficient and ambient temperature. Thus, the heat transfer coefficient was studied to obtain the quantitative relationship between its optimum value and the ambient temperature.

In this study, the ternary polymer lithium-ion battery was investigated and a lumped parameter thermal model was established to analyze the thermal behavior of the electric bus battery system under the operation conditions of the driving cycles of the Harbin city buses. In addition, the quantitative relationship between the optimum heat transfer coefficient of the battery and the ambient temperature was obtained. The relationship between the temperature rise $\left(T_{r}\right)$, the number of cycles $(c)$, and the heat transfer coefficient $(h)$ under three Harbin bus cycles was investigatedat $30^{\circ} \mathrm{C}$, because it can provide a basis for the design of the battery thermal management system. The short version of the paper was presented at ISEV2017 on 26-29 July, Sweden. This paper is a substantial extension of the short version of the conference paper. This paper extends and complements the theories presented in the conference paper [14].

\section{Selection and Calculation of the Test Cycles}

In this study, a cylindrical 2.6 Ah 18650 ternary polymer lithium-ion battery was used as a case study. The basic parameters of the battery are shown in Table 1. 
Table 1. Basic parameters of the 2.6 Ah 18650 ternary polymer lithium-ion battery.

\begin{tabular}{cc}
\hline Parameters & Value \\
\hline Mass $/ \mathrm{g}$ & 45 \\
Radius/mm & 9 \\
Height/mm & 65 \\
Nominal capacity/Ah & 2.6 \\
Nominal voltage/V & 3.6 \\
Charge cutoff voltage/V & 4.2 \\
Discharge cutoff voltage/V & 2.75 \\
\hline
\end{tabular}

The heat transfer coefficient of the battery was studied through the Harbin bus driving cycles. It can provide a theoretical basis for the design of a thermal management system in Harbin [15]. Figures 1-3 show the Harbin city road bus cycle (regular lines), Harbin bus rapid transit cycle (BRT lines), and the Harbin suburban bus cycle (suburban lines), respectively. The main characteristic parameters of the three cycles are shown in Table 2 [16]. The Harbin suburban bus cycle exhibits the maximum speed and maximum acceleration among the three cycles, so the Harbin suburban bus cycle is more severe for EV batteries.

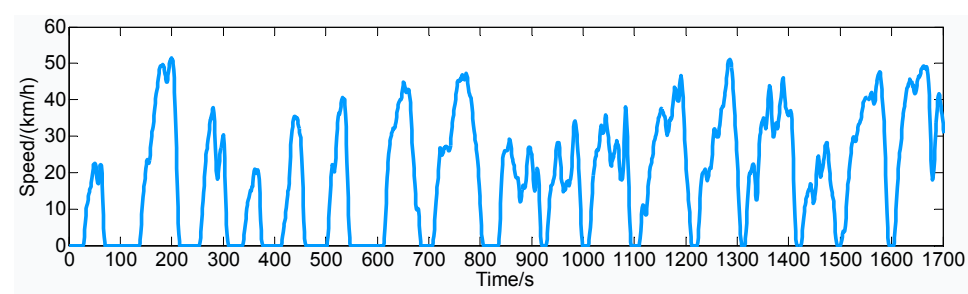

Figure 1. Regular lines.

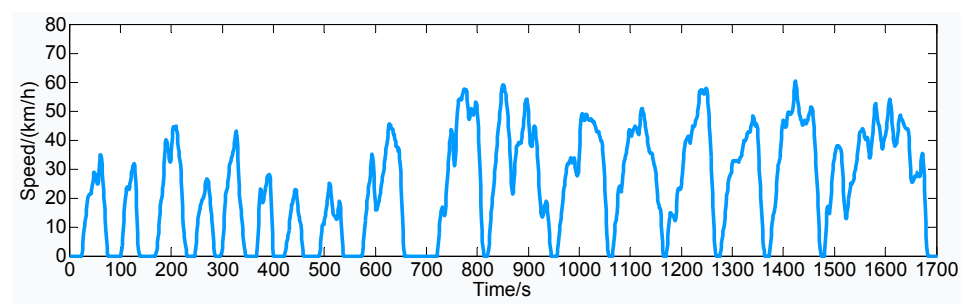

Figure 2. BRT lines.

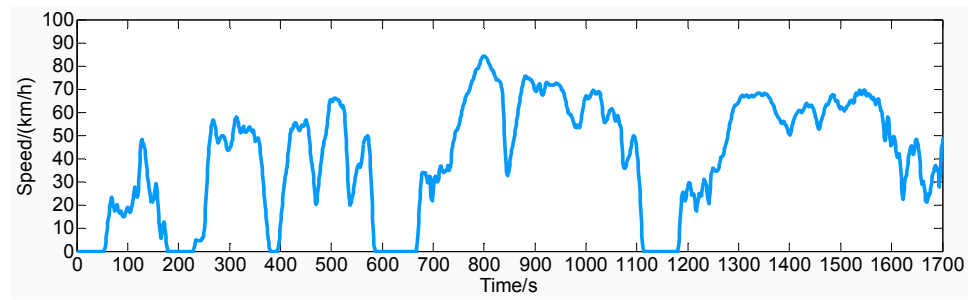

Figure 3. Suburban lines.

Table 2. Characteristic parameters of the test cycles.

\begin{tabular}{ccccc}
\hline & $\begin{array}{c}\text { Average Speed } \\
\mathbf{( k m} / \mathbf{h})\end{array}$ & $\begin{array}{c}\text { Maximum } \\
\text { Speed } \mathbf{( k m} / \mathbf{h})\end{array}$ & $\begin{array}{c}\text { Maximum } \\
\text { Acceleration }\left(\mathbf{m} / \mathbf{s}^{2}\right)\end{array}$ & $\begin{array}{c}\text { Maximum } \\
\text { Deceleration }\left(\mathbf{m} / \mathbf{s}^{\mathbf{2}}\right)\end{array}$ \\
\hline Regular lines & 19.17 & 51.4 & 1.33 & -1.61 \\
BRT lines & 24.73 & 60.4 & 1.5 & -1.72 \\
Suburban lines & 40.44 & 84.2 & 2.5 & -1.89 \\
\hline
\end{tabular}


In this study, the output current of the cell was used as an input condition in the simulation to predict the temperature of the battery under the operation conditions of the three Harbin bus lines. In order to calculate the output current of the battery pack under the operation conditions of the Harbin bus cycles, the instantaneous output power $\left(P_{m}\right)$ of the traction motor should be calculated. When the bus is in transit, the traction motors should overcome the running resistance $\left(F_{t}\right)$, which includes the rolling resistance $\left(F_{f}\right)$, air resistance $\left(F_{w}\right)$, grade resistance $\left(F_{i}\right)$, and acceleration resistance $\left(F_{j}\right)$. The calculations are shown in Equations (1)-(6).

$$
\begin{gathered}
F_{t}=F_{f}+F_{w}+F_{i}+F_{j} \\
F_{f}=f m g \cos \alpha \\
F_{w}=\frac{C_{d} A u_{a}^{2}}{21.15} \\
F_{i}=m g \sin \alpha \\
F_{j}=\delta m d u_{a} / d_{t} \\
\alpha=\tan ^{-1} i
\end{gathered}
$$

The instantaneous output power of the traction motor $\left(P_{m}\right)$ can be calculated by Equation (7).

$$
P_{m}=\frac{F_{t} \cdot u_{a}}{3.6 \eta_{T}}
$$

where $f$ is the rolling resistance coefficient, $m$ is the weight of the bus, $i$ is the gradient, $C_{d}$ is the air resistance coefficient, $A$ is the windward area, $u_{a}$ is the speed of the bus, and $\delta$ is the rotational mass conversion factor.

The instantaneous output power of the traction motor can be calculated based on Equations (1)-(7). The studied bus parameters are shown in Table 3. This study considered $25 \%$ of deceleration power to be applied in order to charge the battery [11]. The instantaneous output power of the traction motor can be converted into the instantaneous output power of the battery pack using the motor efficiency and the inverter efficiency as shown in Equation (8).

$$
P_{b}=\frac{P_{m}}{\eta_{m} \cdot \eta_{\text {inverter }}}
$$

where $\eta_{m}$ is the motor efficiency (90\% in this study) [17] and $\eta_{\text {inverter }}$ is the Inverter efficiency ( $95 \%$ in this study) [18].

When selecting the battery capacity, the maximum output power and energy consumed to meet the requirements of the power performance and endurance mileage are the main parameters to be considered. Moreover, the endurance mileage index is used to calculate the required power battery capacity. To avoid excessive discharge of the batteries, the pure electric mileage is calculated at $75 \%$ of the battery capacity, as shown in Equation (9).

$$
Q_{b a t}=\frac{1}{0.75} \cdot \frac{W_{b a t}}{U_{b a t}}=0.75 \cdot t \cdot \frac{P_{b a t, o u t}}{U_{b a t}}=\frac{1}{0.75} \cdot \frac{s}{u_{a}} \cdot \frac{P_{m}}{U_{b a t}}
$$

where $u_{a}$ is the vehicle speed at the constant speed mode, $s$ is the endurance mileage at the constant speed mode, $P_{b a t, o u t}$ is the battery output power, $U_{b a t}$ is the battery pack terminal voltage, $W_{b a t}$ is the battery energy, and $Q_{b a t}$ is the battery capacity.

The battery capacity meeting the requirements of the endurance mileage can be calculated by Equation (9) (which was found to be $254 \mathrm{Ah}$ in this study). This study assumed that the battery pack terminal voltage is $380 \mathrm{~V}$, the battery capacity is $2.6 \mathrm{Ah}$, and the nominal voltage of the battery is $3.6 \mathrm{~V}$. Moreover, the cells inside the battery pack were 106 in series and 98 in parallel. It was also assumed 
that all the cells have the same characteristics. Therefore, the output current of the cell $\left(I_{\text {cell }}\right)$ can be calculated by Equation (10).

$$
I_{\text {cell }}=\frac{P_{b}}{U_{b a t} \cdot 98}
$$

The calculated output current of the cell under the operation conditions of the three Harbin bus cycles is shown in Figure 4. The result of Equations (1)-(10), which is the output current of the cell, was applied to Equation (12).

Table 3. Parameters of one of the studied electric buses.

\begin{tabular}{cc}
\hline Parameter & Value \\
\hline Length*width*height $/ \mathrm{m}$ & $11.98^{*} 2.55^{*} 3.2$ \\
curb weight $/ \mathrm{kg}$ & 13,400 \\
Full load weight $/ \mathrm{kg}$ & 18,000 \\
Minimum ground clearance $/ \mathrm{mm}$ & 130 \\
Maximum braking distance $/ \mathrm{m}$ & 10 \\
Minimum turning diameter $/ \mathrm{m}$ & 24 \\
Tires & $275 / 70 \mathrm{R} 22.5$ \\
Curb quality $/ \mathrm{kg}$ & $13,400+200$ \\
Bearing quality $/ \mathrm{kg}$ & 4300 \\
Windward area $/ \mathrm{m}^{2}$ & 7.83 \\
Wheel rolling radius $/ \mathrm{m}$ & 0.478 \\
Air resistance coefficient & 0.75 \\
Rolling resistance coefficient & $0.0076+0.000056 u_{a}$ \\
Air density $/\left(\mathrm{kg} / \mathrm{m}^{3}\right.$ ) & 1.23 \\
Main gear ratio & 6.2 \\
Total efficiency of the transmission system & 0.96 \\
\hline
\end{tabular}
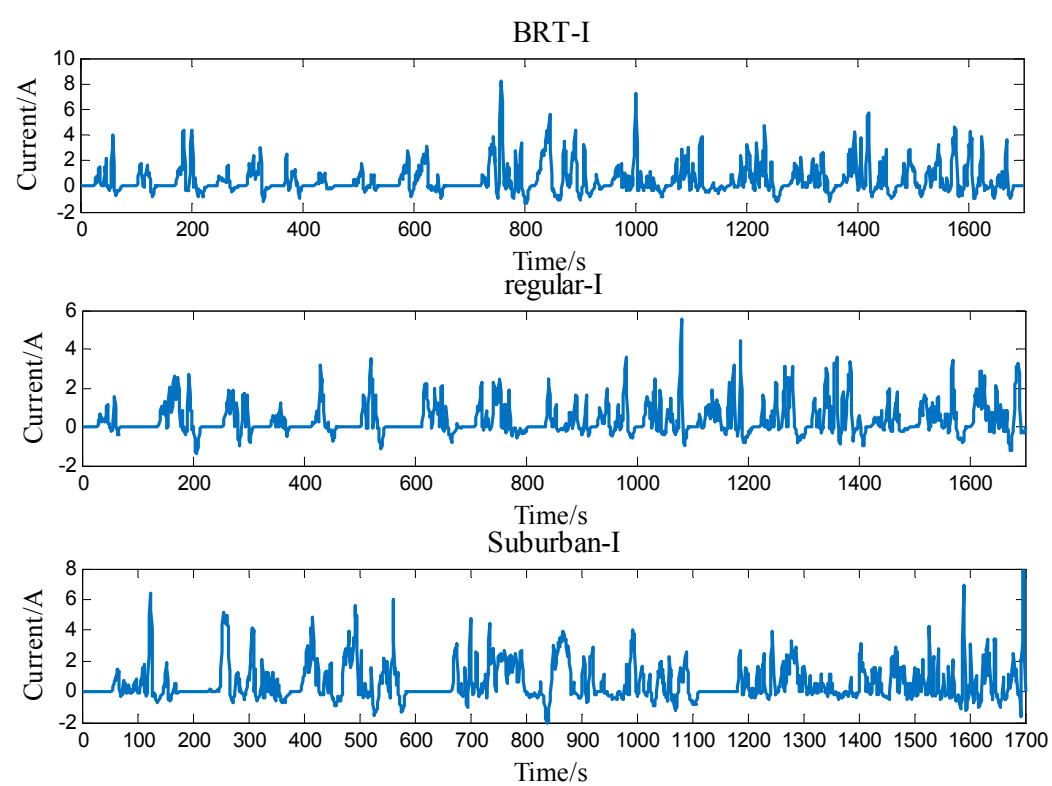

Figure 4. The output current of the cell under the conditions of the three Harbin bus cycles.

\section{Establishment and Verification of the Thermal Model}

\subsection{Simulation Model Building}

To predict the battery temperature and determine the quantitative relationship between the heat transfer coefficient and ambient temperature, a lumped parameter model of the battery was established. In addition, the electrochemical properties inside the battery were assumed to be homogeneous and 
isotropic, the electrolyte inside the battery was assumed to be nearly immobile, and the influence of the internal convection heat transfer was neglected [19].

Equation (11) represents the internal energy conservation equation of the battery [20].

$$
\rho c_{p} \frac{\partial T}{\partial t}=\lambda \nabla^{2} T+q-q_{e}=\lambda_{x} \frac{\partial^{2} T}{\partial x^{2}}+\lambda_{y} \frac{\partial^{2} T}{\partial y^{2}}+\lambda_{z} \frac{\partial^{2} T}{\partial z^{2}}+q-q_{e}
$$

where $q$ is the total heat generation rate of the battery; $q_{e}$ is the heat exchange rate between the battery and the environment; $\rho$ is the average cell density; $c_{p}$ is the heat capacity; and $\lambda_{x}, \lambda_{y}$, and $\lambda_{z}$ represent the thermal conductivity in the direction of $X, Y$, and $Z$, respectively.

The simulated battery can be regarded as a homogeneous heating object, because it is small in size [19]. The total heat generation rate of the battery $(q)$ can be estimated by Equation (12) [21].

$$
q=I\left(U-U_{O C V}\right)+I T \frac{d U_{O C V}}{d T}=I^{2} R+I T \frac{d U_{O C V}}{d T}
$$

As shown in the equation, $U-U_{O C V}$ can be simplified to $I R$, where $R$ is the internal resistance, $\frac{d U_{O C V}}{d T}$ is the entropy coefficient, $T$ is the temperature of the battery, and $I$ is the current of the battery.

The internal resistance of the battery in Equation (12) can be obtained by the hybrid pulse power characterization (HPPC) test [22]. The entropy coefficient can be obtained by the following method $[23,24]$ : the battery open circuit voltage $\left(U_{O C V}\right)$ is measured under fixed SOC (state of charge) conditions and different ambient temperature, and the relation between $U_{O C V}, T_{S}$, and SOC is shown in Figure 5. In this study, the open circuit voltage of the battery was measured under different SOC values at $10,20,30$, and $40^{\circ} \mathrm{C}$. Then, the entropy coefficient can be obtained by fitting a function of the ambient temperature $\left(T_{S}\right)$ and open circuit voltage $\left(U_{O C V}\right)$ at a specified SOC, where the slope of the function is the entropy coefficient. Figure 6 shows the change in the entropy coefficient with the SOC.

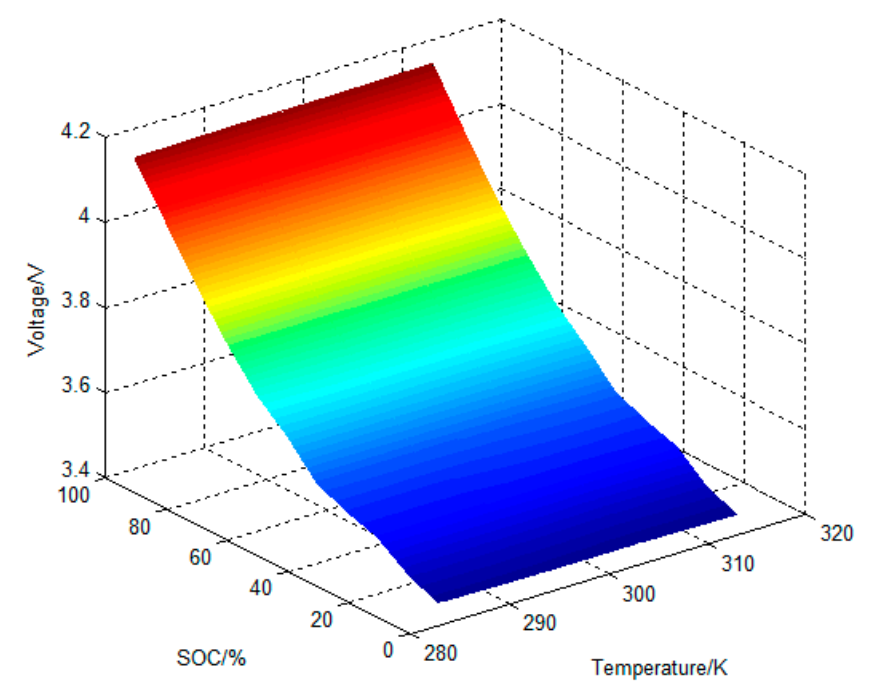

Figure 5. Voltage versus temperature at $60 \%$ SOC.

The heat exchange rate $\left(q_{e}\right)$ between the battery and the environment during charging and discharging can be calculated by Equation (13) [25].

$$
q_{e}=\frac{h A_{c}}{V_{c}}\left(T-T_{s}\right)
$$

where $h$ is the heat transfer coefficient, $V_{c}$ is the unit volume of the cell, and $A_{c}$ is the surface area of the cell. 
In Equation (13), $h$ can be obtained from the temperature curve of the stationary cell. When the batteries are standing, the internal heat generation rate $(q)$ is zero. Thus, Equation (14) can be derived from Equation (11).

$$
\rho c_{p} \frac{\partial T}{\partial t}=-\frac{h A_{c}}{V_{c}}\left(T-T_{s}\right)
$$

Equation (14) takes points on both sides, and Equation (15) can then be derived.

$$
\ln \left(T-T_{S}\right)=-\frac{h A}{\rho V_{c} c_{p}} t+\ln \left(T-T_{s 0}\right)
$$

The slope of the curve of the function of $\ln \left(T-T_{S}\right)$ versus time $(t)$ represents the equivalent heat transfer coefficient. Therefore, the heat transfer coefficient can be obtained by Equation (15).

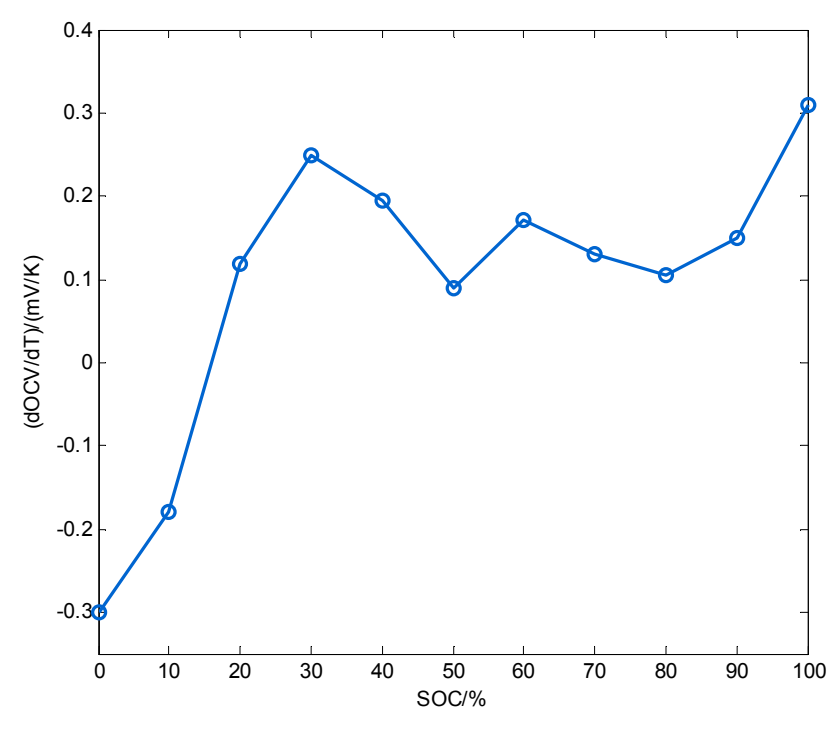

Figure 6. Change in the entropy coefficient with the SOC.

A lithium-ion battery is formed by placing a multilayer electrode and a diaphragm into the electrolyte in the form of a spiral structure; thus, the conductivity inside the battery is anisotropic [20]. In this study, the calculation methods of the average cell density, average density, and average heat capacity of the active material can be obtained by the method mentioned in the study of Du S L [19]. Assuming that the electrical conductivity is equal in the $X$ and $Y$ directions, it can be considered radial conductivity $\left(\lambda_{r}\right)$ and can be obtained by Equation (16).

$$
\lambda_{r}=\frac{\sum \lambda_{i} L_{i}}{\sum L_{i}}
$$

On the other hand, the conductivity in the $Z$ direction is the axial conductivity $\left(\lambda_{a}\right)$ and can be obtained by Equation (17).

$$
\lambda_{a}=\frac{\sum L_{i}}{\sum \frac{L_{i}}{\lambda_{i}}}
$$

The average density of active material $(\rho)$ can be obtained by Equation (18).

$$
\rho=\frac{\sum L_{i} \rho_{i}}{\sum L_{i}}
$$


The average heat capacity of active material $\left(C_{p}\right)$ can be calculated by Equation (19).

$$
c_{p}=\frac{\sum L_{i} c_{p, i}}{\sum L_{i}}
$$

where $\lambda_{r}$ is the radial conductivity, $\lambda_{a}$ is the axial conductivity, $\lambda_{i}$ is the material conductivity, $c_{p, i}$ is the material heat capacity, and $L_{i}$ is the material thickness. The thermal parameters required are given in Table 4, the data in Table 4 are adapted from the reference [19,25-29].

Table 4. Basic thermal parameters of the 18650 ternary polymer lithium-ion batteries. Reprint with permission [26]; 2014, Journal of Power Sources; Reprint with permission [25]; 2012, Journal of Power Sources; Reprint with permission [27]; 2012, Journal of Power Sources; Reprint with permission [28]; 2016, Energies; Reprint with permission [29]; 2015, Energy; Reprint with permission [19]; 2014, Chinese Journal of Nonferrous Metals.

\begin{tabular}{|c|c|c|c|}
\hline Material & $k_{i}\left(\mathrm{~W} \mathrm{~m}^{-1} \mathrm{~K}^{-1}\right)$ & $\rho_{i}\left(\mathrm{~kg} \mathrm{~m}^{-3}\right)$ & $c_{p, i}\left(\mathrm{~J} \mathrm{~kg}^{-1} \mathrm{~K}^{-1}\right)$ \\
\hline Separator [26] & 0.334 & 1009 & 1978.16 \\
\hline Negative electrode & 1.04 [25-27] & 1347.33 [28] & $1437.4[28]$ \\
\hline Positive electrode & $1.58[28]$ & $2328.5[28]$ & $1269.21[28]$ \\
\hline $\mathrm{Al}[29]$ & 160 & 2700 & 903 \\
\hline $\mathrm{Cu}[29]$ & 400 & 8900 & 385 \\
\hline can [19] & 44.5 & 7850 & 475 \\
\hline
\end{tabular}

\subsection{Simulation Model Verification}

To verify the effectiveness of the proposed model, the ternary polymer lithium-ion battery was tested by a battery test system and a thermostat, and the temperature was measured by a temperature acquisition device. The experimental facilities are shown in Figure 7, and the device parameters are listed in Table 5.

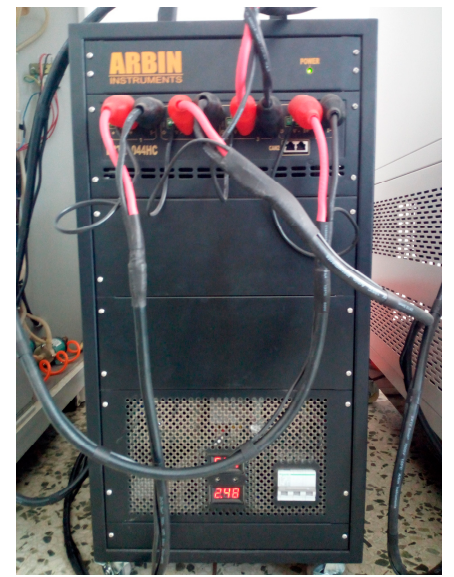

(a)

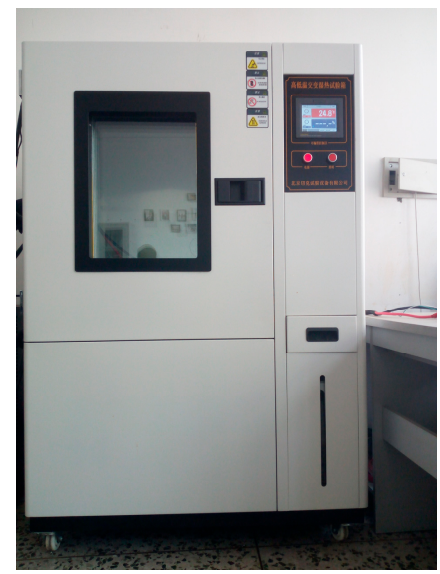

(b)

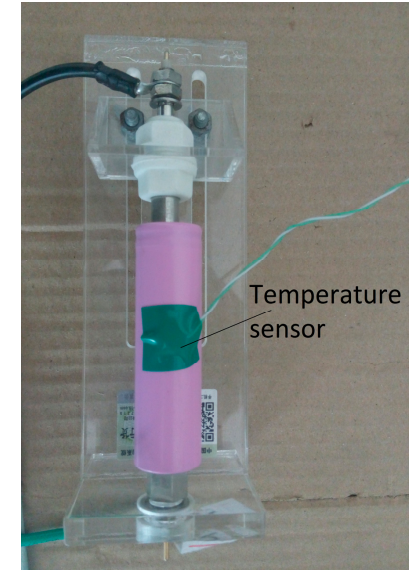

(c)

Figure 7. The experimental facility. (a) Arbin battery test system; (b) Thermostat; (c) Temperature measuring.

In this study, the battery was fully charged by the $0.3 \mathrm{C}$ constant current-constant voltage (CCCV) model at ambient temperature $\left(25^{\circ} \mathrm{C}\right)$, and then the constant discharge test was carried out at different rates $(0.5 \mathrm{C}, 1 \mathrm{C}$, and $2 \mathrm{C})$ at the same temperature after two hours of standing. Next, the changes in the temperature of the battery were measured. The heat transfer coefficient of the test battery was obtained by fitting the curve of $h$ versus temperature after the discharge and was found to be $20 \mathrm{~W} / \mathrm{m}^{2} \mathrm{~K}$. Figure 8 shows the comparison between the experimental and simulation results of constant current discharge with different rates at ambient temperature $\left(25^{\circ} \mathrm{C}\right)$. Figure 8 shows that the experiment 
and the simulation were in good agreement, and the maximum error between the simulation and the experimental results was $0.88^{\circ} \mathrm{C}$. In addition, the temperature error was less than $1{ }^{\circ} \mathrm{C}$, which indicates that the model can accurately predict temperature [21]. In order to verify the accuracy of the simulation model in the actual working conditions, the driving cycle experiment was tested at the same ambient temperature, and the output current of the cell used in regular lines was inputted in the model to simulate a battery that operates under the conditions of the regular lines cycles. The heat transfer coefficient of the testing battery $\left(20 \mathrm{~W} / \mathrm{m}^{2} \mathrm{~K}\right)$ was obtained by fitting the $h-T$ curve after discharge. Figure 9 shows the increase in the battery temperature and the errors between the experimental and simulation results under the operation conditions in regular lines. The absolute error was less than $0.3^{\circ} \mathrm{C}$, which indicates that the model can provide accurate temperature predictions.

Table 5. The device parameters of the experimental facility.

\begin{tabular}{ll}
\hline & Voltage range: $0 \mathrm{~V}-5 \mathrm{~V}$ \\
& Current range: $0 \mathrm{~A}$ \\
Arbin battery test system & -50 AVoltage accuracy: full-range $\pm 0.5 \% \mathrm{FSR}$ \\
& Current accuracy: full-range $\pm 0.1 \% \mathrm{FSR}$ \\
& Number of channels: 4 \\
\hline \multirow{3}{*}{ Thermostat } & Temperature range: $-40-+150{ }^{\circ} \mathrm{C}$ \\
& Temperature error: $<0.5^{\circ} \mathrm{C}$ \\
& Chamber size: $0.5 \mathrm{~m}{ }^{*} 0.5 \mathrm{~m} * 0.6 \mathrm{~m}$ \\
\hline \multirow{3}{*}{ Pico temperature acquisition device } & Sensor type: $\mathrm{K}$ type thermocouple \\
& Temperature accuracy: $\pm 0.2 \%$ reading and $\pm 0.5{ }^{\circ} \mathrm{C}$ \\
& Conversion time: $100 \mathrm{~ms}$ \\
& resolution ratio: 20 bit \\
& Number of channels: 8 \\
\hline
\end{tabular}

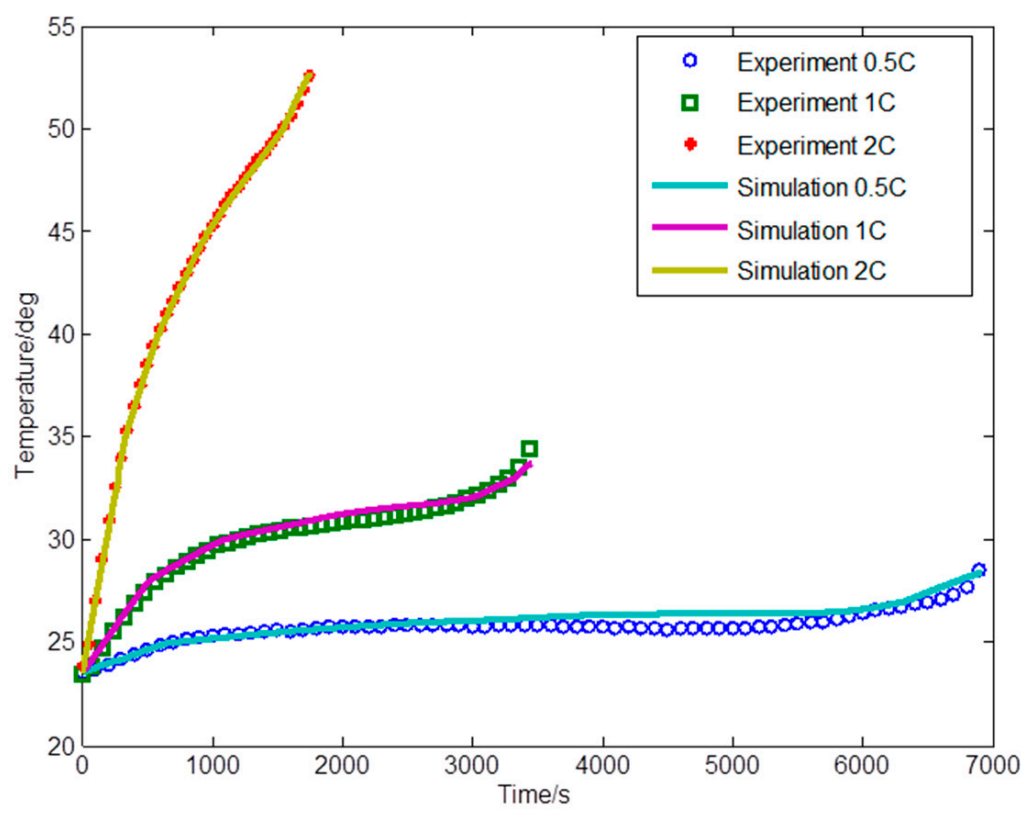

Figure 8. The results of the constant current discharge experiment and simulation. 

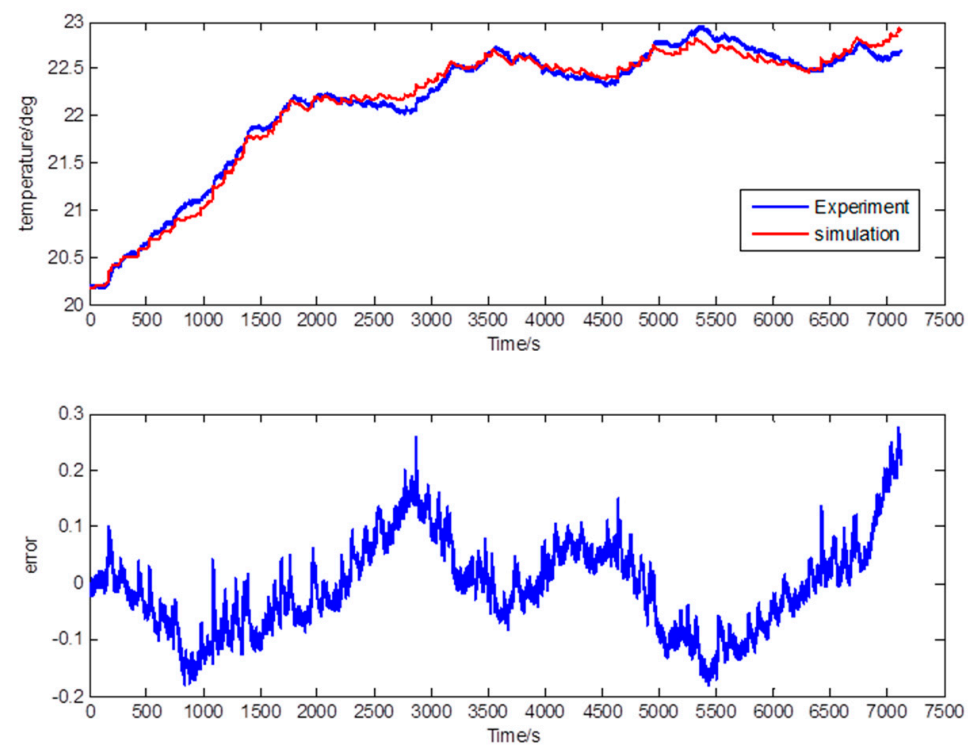

Figure 9. Temperature increase and simulation errors under the operation conditions of the regular lines.

\section{Results and Discussion}

\subsection{Optimum Heat Transfer Coefficient Analysis}

The increase in temperature was investigated after eight cycles, i.e., SOC of the battery was less than $20 \%$, the mileage was about $100 \mathrm{~km}$, the electric bus was running for a long time, and the battery temperature was significantly changing. The simulation was carried out at different heat transfer coefficients of the cell using COMSOL Multiphysics simulation software at $30^{\circ} \mathrm{C}$ under the operation conditions of the regular lines. The initial temperature of the battery was assumed to be similar to the ambient temperature $\left(30^{\circ} \mathrm{C}\right)$, and the natural convection coefficient was $h=7.71 \mathrm{~W} / \mathrm{m}^{2} \mathrm{~K}[30]$. Figure 10 shows the change in the battery temperature after eight cycles under the operation conditions of the regular lines.
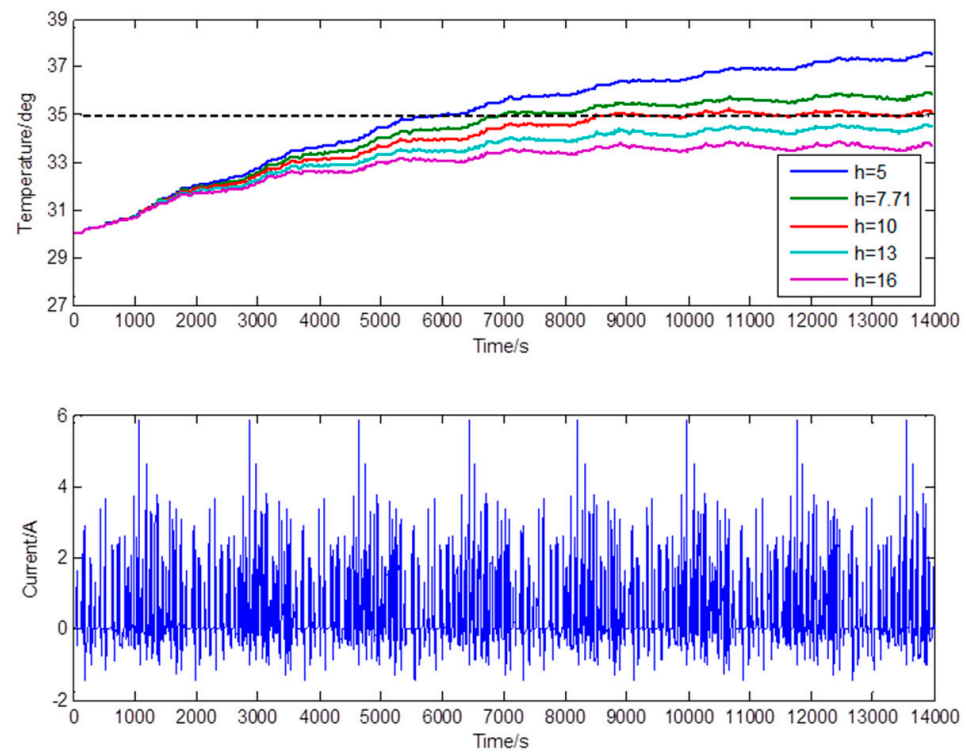

Figure 10. The increase in temperature after eight cycles under the operation conditions of the regular lines. 
To ensure the battery is working properly during the actual operation, the operating temperature of the battery should be kept below $35^{\circ} \mathrm{C}$ [7]. Figure 10 shows that the battery gradually reached a heat balance with the progression of time, and the temperature was stable at the end of the test. When $h$ was $7.71 \mathrm{~W} / \mathrm{m}^{2} \mathrm{~K}$ (natural convection), the temperature increased by about $7.5^{\circ} \mathrm{C}$, i.e., the temperature was more than $37^{\circ} \mathrm{C}$ after eight cycles under the operation conditions of the regular lines. This means that the temperature rises quickly, and hence the natural convection cannot meet the cooling requirements of the batteries. Thus, to make sure the temperature of the battery is below $35^{\circ} \mathrm{C}$ after eight cycles under the operation conditions of the regular lines, $h$ should be more than $10 \mathrm{~W} / \mathrm{m}^{2} \mathrm{~K}$.

In this study, it assumes that the initial SOC of the battery is $90 \%$. According to the thermal model developed in this study, the heat transfer coefficient that ensures the temperature of battery is below $35{ }^{\circ} \mathrm{C}$ after working for eight cycles under the operation conditions of the three Harbin bus lines can be obtained with different ambient temperature, as shown in Figures 11-13. The data were fitted by the least squares method, to obtain the quantitative relationship between the optimum heat transfer coefficient and the ambient temperature of the battery under the operation conditions of the three Harbin bus lines, which are shown in Equations (20)-(22). Figure 11 and Equation (20) show that natural convection can meet the cooling requirements of the batteries under the regular lines when the ambient temperature is below $28^{\circ} \mathrm{C}$, while when the ambient temperature is $30^{\circ} \mathrm{C}$, the heat transfer coefficient should be at least $12 \mathrm{~W} / \mathrm{m}^{2} \mathrm{~K}$. Figure 12 and Equation (21) show that when the ambient temperature is below $23^{\circ} \mathrm{C}$, the natural convection can meet the cooling requirements of the batteries in the BRT lines, while when the ambient temperature is $30^{\circ} \mathrm{C}$, the heat transfer coefficient should be at least $22 \mathrm{~W} / \mathrm{m}^{2} \mathrm{~K}$. Figure 13 and Equation (22) show that when the ambient temperature is below $20^{\circ} \mathrm{C}$, the natural convection can meet the cooling requirements of batteries under the operation conditions of the suburban lines, while when the ambient temperature is $30^{\circ} \mathrm{C}$, the heat transfer coefficient should be at least $32 \mathrm{~W} / \mathrm{m}^{2} \mathrm{~K}$.

$$
\begin{gathered}
h=-81.3+10.743 \mathrm{~T}_{s}-0.488 \mathrm{~T}_{\mathrm{s}}^{2}+0.0078 \mathrm{~T}_{\mathrm{s}}^{3} \\
h=-193.169+25.72 \mathrm{~T}_{s}-1.135 \mathrm{~T}_{\mathrm{s}}^{2}+0.01723 \mathrm{~T}_{\mathrm{s}}^{3} \\
h=-290.92+39.026 \mathrm{~T}_{\mathrm{s}}-1.725 \mathrm{~T}_{\mathrm{s}}^{2}+0.026 \mathrm{~T}_{\mathrm{s}}^{3}
\end{gathered}
$$

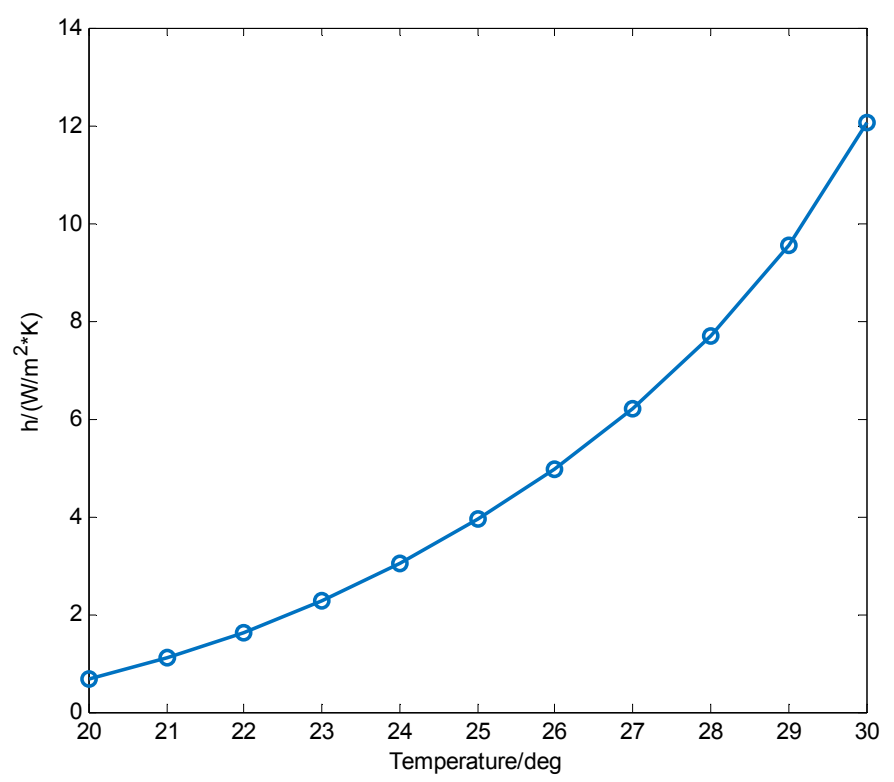

Figure 11. The change in heat transfer coefficient with ambient temperature under the operation conditions of the regular lines. 


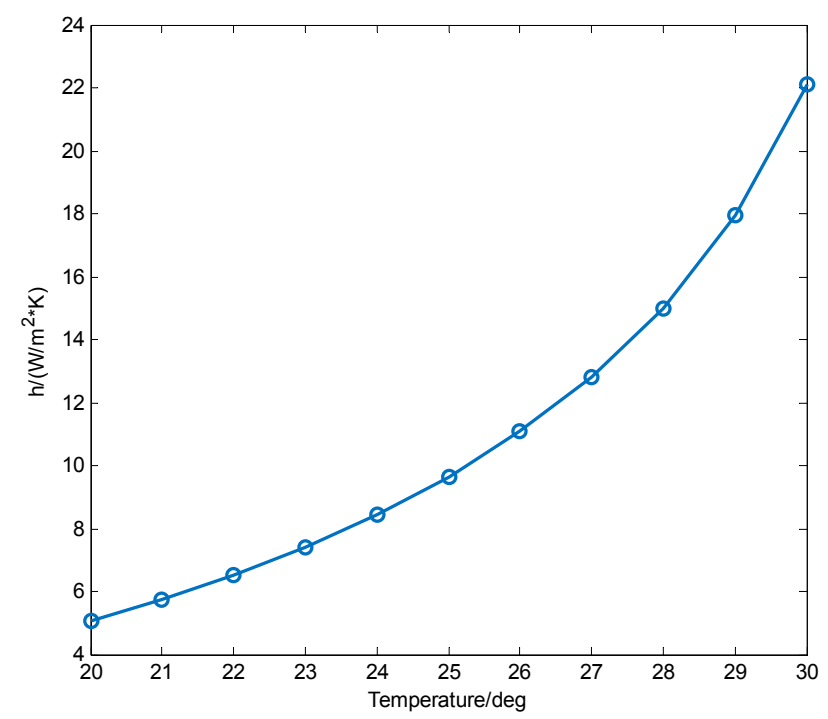

Figure 12. The change in the heat transfer coefficient with ambient temperature under the operation conditions of the BRT lines.

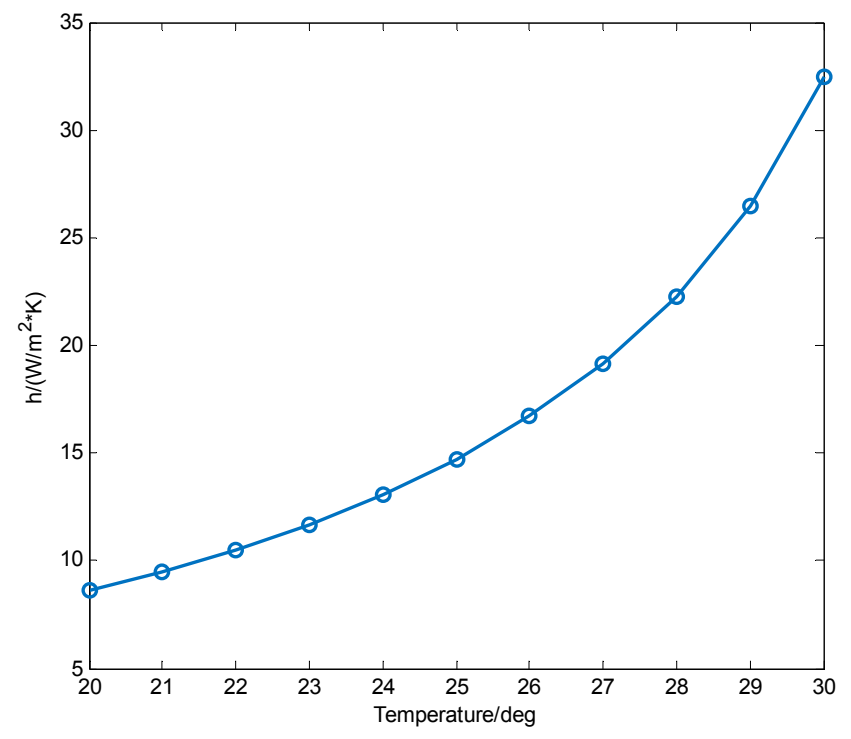

Figure 13. The change in the heat transfer coefficient with ambient temperature under the operation conditions of suburban lines.

This analysis shows that the heat transfer coefficient that meets the requirements of battery thermal management equals the cubic power function of the ambient temperature. Therefore, when the ambient temperature is $30{ }^{\circ} \mathrm{C}$, the heat transfer coefficient should be at least $12 \mathrm{~W} / \mathrm{m}^{2} \mathrm{~K}$ under the operation conditions of the regular lines, $22 \mathrm{~W} / \mathrm{m}^{2} \mathrm{~K}$ under the operation conditions of the BRT lines, and $32 \mathrm{~W} / \mathrm{m}^{2} \mathrm{~K}$ under the operation conditions of suburban lines.

\subsection{Temperature Rise Analysis}

From the simulation results of COMSOL it can be seen that, when the ambient temperature is $30{ }^{\circ} \mathrm{C}$, the temperature rise of the battery is related to the heat transfer coefficient of the battery and 
the number of cycles. Therefore, the temperature rise can be expressed as a function of the number of cycles $(c)$ and the heat transfer coefficient $(h)$, as shown in Equation (23).

$$
T_{r}=f(c, h)
$$

where $T_{r}$ is the temperature rise, $c$ is the number of cycles, and $h$ is the heat transfer coefficient of the battery.

In order to determine the quantitative relationship of the function, this paper used MATLAB simulation software to analysis the data and the multiple linear regression method was adopted.

\subsubsection{Multiple Linear Regression Analysis}

Multivariate linear regression is a mathematical analysis method which was used to derive the relation of the random variables $y$ and variables $x_{1}, x_{2}, \cdots, x_{m}$. Assuming that the variables are linear, the regression equation is shown in Equation (24).

$$
y=\alpha_{0}+\alpha_{1} x_{1}+\cdots+\alpha_{m} x_{m}
$$

where $\alpha_{0}, \alpha_{1}, \cdots, \alpha_{m}$ are regression coefficients and $x_{1}, x_{2}, \cdots, x_{m}$ are regression variables.

To establish a multiple linear regression model, $n$ times independent observed values are needed for regression variables to obtain the observed values $\alpha_{0}, \alpha_{1}, \cdots, \alpha_{m}$ of regression variables. The observed values satisfy Equation (25).

$$
y_{i}=\alpha_{0}+\alpha_{1} x_{1 i}+\alpha_{2} x_{2 i}+\cdots+x_{m i}, \quad i=1,2, \cdots n
$$

In order to determine the quantitative relationship of the function, the relation between the battery temperature rise and the cycles, the relation between the battery temperature rise, and the heat transfer coefficient should be analysed, respectively. Therefore, the simulation data obtained by COMSOL is used as the observation value, and the relation scatter diagram was made by MATLAB software. The relation scatter diagram under the regular lines is shown in Figure 14.

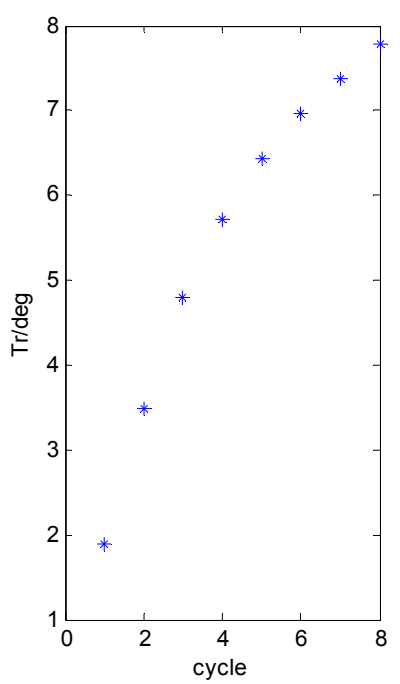

(a)

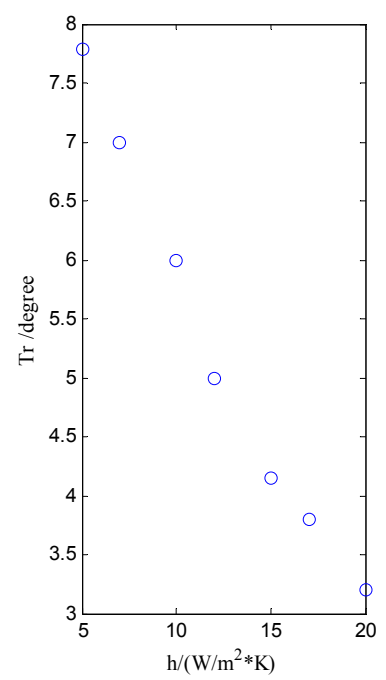

(b)

Figure 14. The relation scatter diagram. (a) The relation between $T_{r}$ and cycle; (b) The relation between $T_{r}$ and $h$.

It can be seen from Figure 14 that the temperature rise $\left(T_{r}\right)$ and the number of cycles $(c)$, and the temperature rise $\left(T_{r}\right)$ and the heat transfer coefficient $(h)$ of the battery are approximately linear. 
Analysed in the same way, it presents the same conclusion under the operation conditions of the BRT lines and suburban lines. Therefore, the $T_{r}$ model is assumed to be a linear regression relation of two variables, as shown in Equation (26).

$$
T_{r}=\alpha_{0}+\alpha_{1} c+\alpha_{2} h, \quad c>1
$$

In order to estimate the values of $\alpha_{0}, \alpha_{1}, \alpha_{2}, n$ times the independent observed values of $T_{r}, c$, and $h$ are obtained by COMSOL, which should meet Equation (26), and they are shown in Equation (27).

$$
\left\{\begin{array}{c}
T_{r, 1}=\alpha_{0}+\alpha_{1} c_{1}+\alpha_{2} h_{1} \\
T_{r, 2}=\alpha_{0}+\alpha_{1} c_{2}+\alpha_{2} h_{2} \\
\vdots \\
T_{r, n}=\alpha_{0}+\alpha_{1} c_{n}+\alpha_{2} h_{n}
\end{array}, \quad c>1\right.
$$

Then, Equation (27) is expressed in matrix form, as shown in Equation (28).

$$
\begin{gathered}
Y=X \alpha \\
Y=\left(\begin{array}{c}
T_{r, 1} \\
T_{r, 2} \\
\vdots \\
T_{r, n}
\end{array}\right) \\
X=\left(\begin{array}{c}
1 c_{1} h_{1} \\
1 c_{2} h_{2} \\
\vdots \\
1 c_{n} h_{n}
\end{array}\right) \\
\alpha=\left(\alpha_{0}, \alpha_{1}, \alpha_{2}\right)^{T}
\end{gathered}
$$

$\hat{\alpha}$ is the estimated values of $\left(\alpha_{0}, \alpha_{1}, \alpha_{2}\right)^{T}$, and according to the idea of least squares, it satisfies the condition of Equation (32).

$$
\sum_{i=1}^{n}\left(T_{r, i}-\sum_{j=1}^{2}\left(c_{i} \widehat{\alpha}_{j}+h_{i} \widehat{\alpha}_{j}\right)\right)^{2}=\min _{\alpha} \sum_{i=1}^{n}\left(T_{r, i}-\sum_{j=1}^{2}\left(c_{i} \alpha_{j}+h_{i} \alpha_{j}\right)\right)^{2}
$$

Using the differential method, Equation (32) can be calculated to Equation (33).

$$
\begin{gathered}
\sum_{i=1}^{n}\left(T_{r, i}-\sum_{j=1}^{2}\left(c_{i} \widehat{\alpha}_{j}+h_{i} \widehat{\alpha_{j}}\right)\right) x_{i}=0, x=c, h \\
\Rightarrow \sum_{i=1}^{n} T_{r, i} x_{i}=\sum_{i=1}^{n} \sum_{j=1}^{2}\left(c_{i} \widehat{\alpha}_{j}+h_{i} \widehat{\alpha}_{j}\right) x_{i}=\sum_{j=1}^{2}\left(\sum_{i=1}^{n}\left(c_{i}+h_{i}\right) x_{i}\right) \widehat{\alpha_{j}}
\end{gathered}
$$

Then, Equation (33) is expressed in matrix form, and $\hat{\alpha}$ can be calculated from Equation (34).

$$
X^{T} Y=\left(X^{T} X\right) \hat{\alpha} \Rightarrow \hat{\alpha}=\left(X^{T} X\right)^{-1} X^{T} Y
$$

Then, the relationship amongst $T_{r}, c$, and $h$ can be calculated by Equation (26) to Equation (34) using MATLAB. When the ambient temperature is $30^{\circ} \mathrm{C}$, the relationship amongst $T_{r}, c$, and $h$ under the operation conditions of the regular lines is shown in Equation (35), under the operation conditions 
of the BRT lines is shown in Equation (36), and under the operation conditions of the suburban lines is shown in Equation (37).

$$
\begin{array}{cc}
T_{r}=4.2653+0.4483 c-0.1807 h, & 1<c<n \\
T_{r}=6.5192+0.5563 c-0.2425 h, & 1<c<n \\
T_{r}=7.767+0.5915 c-0.2565 h, & 1<c<n
\end{array}
$$

where $n$ is the number of cycles when the battery SOC reaches its critical value.

\subsubsection{Significance Test of Regression Equation}

In order to prove the fitting degree of the regression equation, the significance test of the regression equation is necessary. In this paper, the fitting degree of the regression equation to the observed value is determined by the coefficient of determination and the standard deviation reflects its deviation from the observed value.

The coefficient of determination can be calculated by Equation (38).

$$
r^{2}=\frac{\sum\left(\hat{y}_{i}-\bar{y}\right)^{2}}{\sum\left(y_{i}-\hat{y}_{i}\right)^{2}}=\frac{\sum\left(\hat{T}_{\mathrm{r} i}-\overline{T_{\mathrm{r}}}\right)^{2}}{\sum\left(T_{\mathrm{r} i}-\hat{T}_{\mathrm{ri}}\right)^{2}}
$$

where $\hat{y}_{\mathrm{i}}$ is the regression value of variable $y, \bar{y}$ is mean of variable $y$, and $y_{i}$ is the observed value of variable $y$.

The absolute deviation of the regression equation and observed value is defined by standard deviation. It is shown in Equation (39) [31].

$$
S_{y}=\sqrt{\frac{\sum\left(y_{i}-\hat{y}_{i}\right)^{2}}{n-2}}
$$

The significance of the regression equation was tested by MATLAB using Equations (38) and (39). The test results are shown in Table 6. It can be seen from Table 6 that the absolute values of $r^{2}$ are all close to 1 under three Harbin bus cycles and the values of $S_{y}$ are all small, so the regression equation satisfies the requirement of significance.

Table 6. Significance test results.

\begin{tabular}{ccc}
\hline & $r^{2}$ & $S_{y}$ \\
\cline { 1 - 3 } Regular lines & 0.9347 & 0.3193 \\
BRT lines & 0.9505 & 0.4523 \\
Suburban lines & 0.8917 & 0.6978 \\
\hline
\end{tabular}

\section{Conclusions}

A ternary polymer lithium-ion battery was used in this study. In addition, a lumped parameter thermal model was established to analyze the thermal behavior of the electric bus battery system running under the operation conditions of the Harbin city bus driving cycles. The quantitative relationship between the optimum heat transfer coefficient of the battery and the ambient temperature was investigated. The relationship amongst the temperature rise $\left(T_{r}\right)$, the number of cycles $(c)$, and the heat transfer coefficient $(h)$ under three Harbin bus cycles wasinvestigated at $30{ }^{\circ} \mathrm{C}$, because it can provide the basis for the design of the battery thermal management system. 
(1) Based on a lumped parameter thermal model, the thermal behavior of the cells was predicted, with different ambient temperature, heat transfer coefficient, and battery current values. The simulation and experimental results show that the model can accurately predict the change in the battery temperature, where the prediction error is less than $1^{\circ} \mathrm{C}$. In addition, in order to keep the temperature of the battery below $35^{\circ} \mathrm{C}$, the quantitative relationship between the optimum heat transfer coefficient and the ambient temperature of the battery was obtained. The results show that the heat transfer coefficient is the cubic power function of the ambient temperature, i.e., when the ambient temperature is $30{ }^{\circ} \mathrm{C}$, the heat transfer coefficient should be at least $12 \mathrm{~W} / \mathrm{m}^{2} \mathrm{~K}$ under the operation conditions of the regular lines, $22 \mathrm{~W} / \mathrm{m}^{2} \mathrm{~K}$ under the operation conditions of the BRT lines, and $32 \mathrm{~W} / \mathrm{m}^{2} \mathrm{~K}$ under the operation conditions of the suburban lines.

(2) When the ambient temperature is $30^{\circ} \mathrm{C}$, the relationship between the temperature rise $\left(T_{r}\right)$, the number of cycles $(c)$, and the heat transfer coefficient $(h)$ under three Harbin bus cycles was investigated. The results show that the temperature rise $\left(T_{r}\right)$ and the number of cycles $(c)$, and the temperature rise $\left(T_{r}\right)$ and the heat transfer coefficient $(h)$ of the battery are approximately linear.

Acknowledgments: This study is supported by the Visiting Scholarship of State Key Laboratory of Power Transmission Equipment \& System Security and New Technology (Chongqing University) (2007DA10512716416) and Science Funds for the Young Innovative Talents of HUST No. 201503 and National Natural Science Foundation of China (51377149) and University Nursing Program for Young Scholars with Creative Talents in Heilongjiang Province (UNPYSCT-2016164).

Author Contributions: Xiaogang $\mathrm{Wu}$ conceived and designed the experiments; Siyu Lv performed the experiments and analyzed the data; Jizhong Chen and Xiaogang $\mathrm{Wu}$ contributed experimental facility and analysis tools; Xiaogang $\mathrm{Wu}$ and Siyu Lv wrote the paper.

Conflicts of Interest: The authors declare no conflict of interest.

\section{References}

1. Chacko, S.; Charmer, S. Concept development and CAE for EV battery thermal management. In Proceedings of the IMechE Conference VTMS10 2011, Gaydon, UK, 15-19 May 2011. C1305-028.

2. Yu, Q.; Xiong, R.; Lin, C.; Shen, W.; Deng, J. Lithium-ion battery parameters and state-of-charge joint estimation based on h infinity and unscented kalman filters. IEEE Trans. Veh. Technol. 2017, 66, 8693-8701. [CrossRef]

3. Tourani, A.; White, P.; Ivey, P. A multi scale multi-dimensional thermo electrochemical modelling of high capacity lithium-ion cells. J. Power Sources 2014, 255, 360-367. [CrossRef]

4. Lin, C.; Xu, S.; Li, Z.; Li, B.; Chang, G.; Liu, J. Thermal analysis of large-capacity $\mathrm{LiFePO}_{4}$ power batteries for electric vehicles. J. Power Sources 2015, 294, 633-642. [CrossRef]

5. Jiang, F.; Peng, P.; Sun, Y. Thermal analyses of $\mathrm{LiFePO}_{4}$ / graphite battery discharge processes. J. Power Sources 2013, 243, 181-194. [CrossRef]

6. Du, S.; Jia, M.; Cheng, Y.; Tang, Y.; Zhang, H.; Ai, L.; Zhang, K.; Lai, Y. Study on the thermal behaviors of power lithium iron phosphate (LFP) aluminum-laminated battery with different tab configurations. Int. J. Therm. Sci. 2015, 89, 327-336. [CrossRef]

7. Saw, L.H.; Somasundaram, K.; Ye, Y.; Tay, A.A.O. Electro-thermal analysis of Lithium Iron Phosphate battery for electric vehicles. J. Power Sources 2014, 249, 231-238. [CrossRef]

8. Chacko, S.; Chung, Y.M. Thermal modelling of Li-ion polymer battery for electric vehicle drive cycles. J. Power Sources 2012, 213, 296-303. [CrossRef]

9. Zou, C.; Manzie, C.; Nesic, D. A Framework for simplification of pde-based lithium-ion battery models. IEEE Trans. Control Syst. Technol. 2016, 24, 1594-1609. [CrossRef]

10. Zou, C.; Hu, X.; Wei, Z.; Tang, X. Electrothermal dynamics-conscious lithium-ion battery cell-level charging management via state-monitored predictive control. Energy 2017, 141, 250-259. [CrossRef]

11. Tourani, A.; White, P.; Ivey, P. Analysis of electric and thermal behaviour of lithium-ion cells in realistic driving cycles. J. Power Sources 2014, 268, 301-314. [CrossRef]

12. Zhang, J.; Bin, W.U.; Zhe, L.I. Thermal modeling and thermal design of lithium-ion batteries for automotive application: Status and prospects. J. Integr. Technol. 2014, 3, 18-26. 
13. Jiaqiang, E.; Long, Y.; Wang, S. Thermal simulation on dynamic lithium-ion battery during charge and its grey relational analysis. J. Cent. South Univ. 2013, 44, 998-1005.

14. Wu, X.; Lv, S. Determination of the optimum heat transfer coefficient for power battery thermal management system under the operation conditions of Harbin city bus driving cycles. In Proceedings of the International Symposium on Electric Vehicles, Stockholm, Sweden, 26-29 July 2017.

15. Chen, C.; Xiong, R.; Shen, W. A lithium-ion battery-in-the-loop approach to test and validate multi-scale dual $\mathrm{h}$ infinity filters for state of charge and capacity estimation. IEEE Trans. Power Electron. 2018, 33, 332-342. [CrossRef]

16. Wu, X.; Hu, C.; Du, J. Development of a driving cycle for city bus in Harbin of China. Int. J. Electr. Hybrid Veh. 2015, 7, 104-119. [CrossRef]

17. Li, W.; Wang, J.; Yang, H.; Gu, Y.; Yang, H.; He, X. A Synchronverter-based V2G smart charging and discharging control strategy for electric vehicles. Proc. CSEE 2017, 37, 544-556.

18. Song, Z.; Hofmann, H.; Li, J.; Hou, J.; Han, X.; Ouyang, M. Energy management strategies comparison for electric vehicles with hybrid energy storage system. Appl. Energy 2014, 134, 321-331. [CrossRef]

19. Du, S.L.; Lai, Y.Q.; Jia, M.; Cheng, Y.; Zhang, H.L.; Zhang, K.; Liu, Y.X. Electrothermal characteristics simulation of cylindrical automotive lithium-ion battery. Chin. J. Nonferrous Met. 2014, 24, 1823-1830.

20. Saw, L.H.; Ye, Y.; Tay, A.A.O. Electrochemical-thermal analysis of 18650 Lithium Iron Phosphate cell. Energy Convers. Manag. 2013, 75, 162-174. [CrossRef]

21. Sun, J.; Wei, G.; Pei, L.; Lu, R.; Song, K.; Wu, C.; Zhu, C. Online internal temperature estimation for lithium-ion batteries based on kalman filter. Energies 2015, 8, 4400-4415. [CrossRef]

22. Xiong, R.; Tian, J.; Mu, H.; Wang, C. A systematic model-based degradation behavior recognition and health monitoring method for lithium-ion batteries. Appl. Energy 2017. [CrossRef]

23. Zou, C.; Manzie, C.; Nešić, D.; Kallapur, A.G. Multi-time-scale observer design for state-of-charge and state-of-health of a lithium-ion battery. J. Power Sources 2016, 335, 121-130. [CrossRef]

24. Xiong, R.; Yu, Q.; Wang, L.Y.; Lin, C. A novel method to obtain the open circuit voltage for the state of charge of lithium ion batteries in electric vehicles by using $\mathrm{H}$ infinity filter. Appl. Energy 2017. [CrossRef]

25. Ye, Y.; Shi, Y.; Tay, A.A.O. Electro-thermal cycle life model for lithium iron phosphate battery. J. Power Sources 2012, 217, 509-518. [CrossRef]

26. Li, J.; Cheng, Y.; Jia, M.; Tang, Y.; Lin, Y.; Zhang, Z.; Liu, Y. An electrochemical-thermal model based on dynamic responses for lithium iron phosphate battery. J. Power Sources 2014, 255, 130-143. [CrossRef]

27. Ye, Y.; Shi, Y.; Cai, N.; Lee, J.; He, X. Electro-thermal modeling and experimental validation for lithium ion battery. J. Power Sources 2012, 199, 227-238. [CrossRef]

28. Melcher, A.; Ziebert, C.; Rohde, M.; Seifert, H. Modeling and simulation the thermal runaway behavior of cylindrical li-ion cells-Computing of critical parameter. Energies 2016, 9, 292. [CrossRef]

29. Xu, M.; Zhang, Z.; Wang, X.; Jia, L.; Yang, L. A pseudo three-dimensional electrochemical-thermal model of a prismatic $\mathrm{LiFePO}_{4}$ battery during discharge process. Energy 2015, 80, 303-317. [CrossRef]

30. Lai, Y.; Du, S.; Ai, L.; Ai, L.; Cheng, Y.; Tang, Y.; Jia, M. Insight into heat generation of lithium ion batteries based on the electrochemical-thermal model at high discharge rates. Int. J. Hydrogen Energy 2015, 40, 13039-13049. [CrossRef]

31. Xiong, R.; Zhang, Y.; He, H.; Zhou, X.; Pecht, M.G. A double-scale, particle-filtering, energy state prediction algorithm for lithium-ion batteries. IEEE Trans. Ind. Electron. 2017, PP, 1. [CrossRef]

(C) 2017 by the authors. Licensee MDPI, Basel, Switzerland. This article is an open access article distributed under the terms and conditions of the Creative Commons Attribution (CC BY) license (http://creativecommons.org/licenses/by/4.0/). 